\title{
Deleuze, Resnais y Prigogine: El año pasado en Marienbad y los sistemas dinámicos inestables
}

\author{
Deleuze, Resnais and Prigogine: The Last Year at Marienbad and \\ Unstable Dynamical Systems
}

\section{Ronald Durán Allimant*}

Universidad de Playa Ancha, Valparaíso, Chile

\section{Resumen}

Siguiendo lo expresado o sugerido por el filósofo francés Gilles Deleuze en su libro La imagen-tiempo: Estudios sobre cine 2, interpretamos, en el presente artículo, el film El año pasado en Marienbad del director francés Alain Resnais como un sistema dinámico inestable o caótico, teniendo como base las ideas del físico-químico llya Prigogine. Consideraremos los elementos visuales y sonoros de la película de Resnais como sistemas dinámicos que entran en relaciones de sincronía y asincronía, estableciendo de esta manera una compleja dinámica de regularidad y caos. Además, analizaremos algunos aspectos del espacio visual y del movimiento, gestos y corporalidad de los personajes desde esta perspectiva.

Palabras clave: Dinámica. Imágenes. Caos. Orden. Inestabilidad.

* RDA: Doctor en Filosofía, e-mail: ronald.duran@upla.cl 


\section{Abstract}

Following what Deleuze expresses or suggests in Cinema II: The Time-Image, in this paper we interpret Alain Resnais' film The Last Year at Marienbad, as an unstable or chaotic dynamical system, based on chemical physicist llya Prigogine's ideas. We consider film's visual and sound elements as dynamical systems coming into synchrony and asynchrony relations, establishing a complex dynamic of regularity and chaos. We also discuss some aspects of the visual space and movements, gestures, and corporality of the movie characters from this perspective.

Keywords: Dynamics. Images. Chaos. Order. Instability.

\section{Introducción}

En su libro La imagen-tiempo: Estudios sobre el cine 2 (2004), el filósofo francés Gilles Deleuze se refiere a algunas nociones de la teoría de sistemas dinámicos inestables, tal como son expuestas por el físico-químico ruso-belga Ilya Prigogine (DELEUZE, 2004, p. 162). Relaciona explícitamente las ideas de Prigogine, con las del director francés Alain Resnais, y con las de Bergson. La llamada «transformación del panadero», con la que Prigogine intenta establecer una suerte de «edades» inscritas en la propia materia, en sistemas dinámicos inestables o caóticos, es relacionada por Deleuze con las capas de memoria de Bergson (2006, p. 172; DELEUZE, 2004, p. 113), y con el cine de la memoria de Resnais (DELEUZE, 2004, p. 162). En particular, la película El año pasado en Marienbad (L'annèe dernière à Marienbad, 1961), sería un juego de capas de memoria de los protagonistas. Respecto a la conexión entre Prigogine y Resnais, Deleuze nos dice: «Resnais no aplica los datos de la ciencia al cine, sino que con sus propios recursos cinematográficos crea algo que tiene su correspondiente en las matemáticas y en la física [...] Puede hablarse de una relación implícita entre Resnais y Prigogine» (DELEUZE, 2004 p. 162). En efecto, Resnais y Prigogine en sus respectivos ámbitos trataron de reivindicar el tiempo, un tiempo constitutivo, creativo, no 
mera medida del movimiento. La obra de Prigogine es un intento de temporalizar la materia (DURÁN, 2013). El cine del director francés es un cine del tiempo, de la memoria (DELEUZE, 2004, p. 158).

Deleuze, sin embargo, no desarrolla con más detalle esta posible conexión entre Prigogine y Resnais, en particular entre las ideas del primero respecto a sistemas dinámicos inestables y la película $E l$ año pasado en Marienbad de Resnais. Creemos, no obstante, que esta conexión puede desarrollarse aún más. Los conceptos aportados por las teorías de Prigogine pueden ser una interesante clave de lectura de la película. El año pasado en Marienbad expone sutiles juegos de regularidad e irregularidad, de estabilidad e inestabilidad, de orden y caos, que los conceptos de sistemas dinámicos inestables pueden ayudarnos a seguir. Así, el film de Resnais, puede ser interpretado como una suerte de «sistema dinámico de imágenes» inestable o caótico, cuya dinámica podría comprenderse como asociada a un «atractor extraño» conjugando orden y caos (caosmos), una suerte de coherencia en tensión, con sus subsistemas entrando en diversas relaciones de sincronía y asincronía. Es lo que trataremos de mostrar en este artículo.

\section{El año pasado en Marienbad: coherencia en tensión}

Existen dos aspectos de la imagen-tiempo: la serie del tiempo según el antes y el después, y el orden del tiempo, según la coexistencia de sus propias relaciones. El primer aspecto constituye un cine del cuerpo, el segundo, un cine del cerebro. Ambos abstractos y concretos a la vez. El cine del cerebro se expresa a través de capas de pasado y presentes simultáneos (DELEUZE, 2004, p. 363). En el film de Alain Resnais El año pasado en Marienbad, el cine del cuerpo y el cine del cerebro se articulan de manera perfecta, por eso esta película constituye una imagen-tiempo directa (DELEUZE, 2004, p. 364) ${ }^{1}$.

1 Para detalles sobre el contexto de producción y lanzamiento de la película, cf. LOSILLA, 2009, p. 5. 
En un primer nivel «narrativo» El año pasado en Marienbad consiste en que un hombre X (Giorgio Albertazzi) ${ }^{2}$ trata de convencer a una mujer A (Delphine Seyrig) de que se han conocido y tenido un amorío el año pasado ¿en Marienbad?. Según X, habían quedado de acuerdo para escabullirse juntos, abandonando ella a su supuesto marido, el hombre M (Sacha Pitoeff). El film, sin embargo, permite otras lecturas, a partir de las preguntas sin respuesta que plantea: « ¿Se conocieron $X$ y A el año pasado en Marienbad (o en otro lugar)? ¿Prometió A huir con X? ¿Está casada con M? ¿Disparó (o dispara) M a A?, etc.» (O’DONOGHUE, 2004).

Como en sus anteriores films, Resnais contó con un guionista de primer nivel para El año pasado en Marienbad: Alain Robbe-Grillet. Sin embargo, éste fue más que un mero guionista y podemos hablar con toda propiedad de un film Resnais - Robbe-Grillet. Éste último dice en una entrevista:

Escribí tres argumentos en una noche y se los llevé a Resnais a quien no conocía [...] Aceptó que yo escribiera directamente la película. No sólo un argumento, sino directamente el guión técnico, plano por plano, con los movimientos de cámara y todo (PEÑA, s.f.).

La relación que se establece entre ambos es «problemática», pues cada uno tenía una manera particular de enfocar la película, o mejor dicho, de crear la película.

Instructiva es la confrontación de Robbe-Grillet y Resnais en El año pasado en Marienbad. Lo que parece extraordinario en esta colaboración es que dos autores (pues Robbe-Grillet no fue solamente guionista) hayan producido una obra tan consistente a pesar de concebirla de maneras tan distintas, casi opuestas (DELEUZE, 2004, p. 141).

Robbe-Grillet nos dice:

Es un film muy raro, porque verdaderamente tiene dos autores. Resnais quería hacer un film sobre la memoria y yo quería hacer un film sobre la persuasión. La idea de la memoria es una cuestión totalmente imaginaria: todo sucede en el presente, ahora aquí. $\mathrm{Y}$ en cuanto a la persuasión,

2 Estos nombres para los personajes no son mencionados en el film, sino que están escritos en el guión. 
a veces me preguntan si Marienbad es acerca de un hombre que quiere persuadir a una mujer para que lo siga. Yo respondo que no, que es acerca de un escritor que quiere persuadir a un director para hacer un film de vanguardia (PEÑA, s.f.).

Como vemos, para Resnais sería un film acerca de la memoria, siguiendo en la línea de sus documentales y largometrajes anteriores (Hiroshima mon amour, Nuit et Brouillard, Guernica, etc.), pero en el que estaría ausente explícitamente el tema de la guerra, en tanto que para Robbe-Grillet todo pasaría en la «cabeza del protagonista», y siguiendo su estilo literario desarrollado en sus novelas, se trataría de un "presente perpetuo». Así pues, la de Resnais sería una exploración de las capas de pasado, mientras que la de Robbe-Grillet sería de presentes simultáneos, de «puntas de presente desactualizadas». Dos maneras complementarias de «acceder» a la imagen-tiempo que hacen de El año pasado en Marienbad un film muy complejo, que admite diversas interpretaciones y deja preguntas abiertas que no tiene sentido tratar de contestar de manera absoluta.

Ahora bien, la doble autoría de El año pasado en Marienbad, no puede expresarse meramente asociando los elementos visuales a Resnais y la narración y el guión a Robbe-Grillet, pues como veíamos, este último no escribió solamente el argumento sino incluso el guión técnico. Por su parte, Resnais hizo alteraciones y contribuciones propias al guión, en especial al personaje A. También queda de manifiesto esta compleja dialéctica en la música de la película, pues en principio estaba determinada por el guión de Robbe-Grillet, pero:

Resnais hizo sustituciones liberales en la música. Donde el autor [RobbeGrillet] solicita una ruidosa orquesta, el director provee un solitario gemido de órgano en clave menor [...] Para el resto de la música, puede haber habido motivos financieros. [...] Parece claro que el sentimiento de la música está mucho más en el dominio del director (asistido por Francis Seyrig) que en el escritor. Resnais despliega una sensibilidad por el órgano, tanto como Ingmar Bergman por el cello (KIRSCH, 1996).

El enfoque de Resnais de capas de pasado puede entenderse así: tenemos dos memorias en juego que comparten algo en común 
(el supuesto encuentro el año pasado). Por un lado está el hombre X que se ubica en una capa de su memoria en la cual conoció a la mujer A. Por su parte, A se ubica en una capa de su memoria en la cual no es claro si conoció o no a X. «En El año pasado en Marienbad, la situación de dos personajes, A y X, es tal que $X$ se posa sobre una capa donde está muy próxima a $\mathrm{A}$, mientras que A se encuentra sobre una capa de otra edad en la que ella está, por el contrario, distante y separada de X» (DELEUZE, 2004, p. 162). Ahora bien, como cada capa de pasado tiene sus "puntos brillantes», sus «centros de gravedad» alrededor de los cuales «giran» los demás recuerdos, podríamos pensar incluso que A y X están en capas de la misma «edad», pero que mientras $X$ tiene como punto brillante el momento en que conoció a A, ella tiene otro punto brillante y su encuentro con $X$ no es más que un recuerdo perdido (DELEUZE, 2004, p. 160).

El otro aspecto en juego, principalmente desarrollado por RobbeGrillet, son «las puntas de presente desactualizadas». Presente desactualizado, que es válido para el conjunto del tiempo y que es al presente actual, lo que los recuerdos puros son a la imagen-recuerdo. El presente desactualizado es el tiempo como duración del acontecimiento. Las diversas posibilidades del acontecimiento están todas en un mismo pie. Los mundos posibles de Leibniz realizados en un mismo mundo. Se está en un «presente perpetuo»: pasado-presente, presente-presente, futuro-presente.

Si El año pasado en Marienbad pudiera dividirse, se diría que el hombre X está más cerca de Resnais, y la mujer A más cerca de Robbe-Grillet. En efecto, el hombre intenta volver a la mujer en capas continuas de las que el presente no es sino la más angosta, como el recorrido de una ola, mientras que la mujer, unas veces dudosa, otras resistiéndose y otras casi convencida, salta de un bloque a otro [bloques de presente], no deja de franquear un abismo entre dos puntas, entre dos presentes simultáneos (DELEUZE, 2004, p. 143).

El hombre X siempre está hablando del pasado, del supuesto encuentro con A. La mujer A habla poco, en general sólo asiente o disiente, pasando constantemente de la aceptación al rechazo, como si lo 
conociera y luego ya no. Cuando $X$ le muestra a A una fotografía que le sacó a ella sentada en una banca, supuestamente el año pasado, ella parece asentir que así fue, pero luego enérgicamente lo niega como temiendo algo. «-¿Qué habitación? Nunca he estado en ninguna habitación contigo. - No quieres recordar, porque estás asustada. ¿Tampoco reconoces esta fotografía? - No lo sé. No recuerdo. - Sabes quién la hizo. - Mientes. - Sabes que fue el año pasado. Te pedí que me dejaras hacerla. Dijiste que te sentirías incómoda. - Sí, tenía razón». Además, las actitudes de A son ambiguas, a veces coquetas como siguiendo el juego, otras son de rechazo, pero no completo, ni con gran energía.

Los diversos juegos de orden y caos, de regularidad e irregularidad, que presenta El año pasado en Marienbad, atribuido en cierta medida por Deleuze a su doble autoría, pueden ser analizados de manera fructífera siguiendo los conceptos de la teoría de sistemas dinámicos inestables. Antes de hacerlo, veamos de manera general, algunos de los conceptos propios de esta teoría, tal como son expuestos y usados por Prigogine.

\section{Sistemas dinámicos inestables o caóticos: orden-y-caos (caosmos)}

De manera general, un sistema dinámico es simplemente un conjunto de elementos o variables (sistema) que varían en el tiempo. Estos sistemas pueden ser estables o inestables. Los primeros, lineales o de equilibrio, implican estados o soluciones estables. En ellos prima el orden y la regularidad del reposo, como en el péndulo de un reloj. «Tomemos un péndulo y estudiemos su movimiento considerando la existencia de una fricción [...] A una pequeña perturbación seguirá un retorno al equilibrio. El estado de equilibrio del péndulo es estable» (PRIGOGINE, 1994, p. 33). Por su parte, los sistemas inestables, no-lineales, irreversibles, implican estados asociados a comportamientos irregulares, no periódicos, caóticos. En estos sistemas inestables lo aleatorio cobra un rol activo y pequeñas diferencias se amplifican en el tiempo, como sucede en turbulencias, en fenómenos meteorológicos, o en un ejemplo tan cotidiano como un lápiz puesto de punta. 
Si logramos sujetar un lápiz en su extremo, el equilibrio será inestable. La menor perturbación lo precipitará a un lado o al otro. Existe una distinción fundamental entre los movimientos estables e inestables. En pocas palabras, los sistemas dinámicos estables son aquellos en los que pequeñas modificaciones de las condiciones iniciales producen pequeños efectos. Pero para una clase muy basta de sistemas dinámicos dichas modificaciones se amplían con el tiempo. Los sistemas caóticos son un ejemplo extremo de sistemas inestables: en ellos las trayectorias correspondientes a condiciones iniciales tan vecinas como se quiera divergen de manera exponencial con el tiempo. Entonces hablamos de "sensibilidad a las condiciones iniciales", y lo ilustramos con la conocida parábola del "efecto mariposa", que dice que el aleteo de una mariposa en la cuenca amazónica puede afectar el clima de Estados Unidos (PRIGOGINE, 1996, p. 33).

El comportamiento o la evolución de los sistemas dinámicos se expresa o grafica en espacios de fases, que representan la evolución de las variables del sistema. En el espacio de fases se muestran todos los estados posibles del sistema, dentro de los cuales encontramos conjuntos de estados estables del sistema: los atractores del sistema. Como describe Prigogine:

El péndulo real, que se va inmovilizando progresivamente, alcanza su estado atractor [...] Se han descubierto nuevos tipos de 'atractores', que enriquecen la dialéctica de lo regular y lo aleatorio [...] Dichos atractores no corresponden a un punto, como en el estado de equilibrio, o a una línea, como en el ciclo límite, sino a un conjunto denso de puntos, lo bastante denso como para que sea posible encontrar puntos en cualquier zona del mismo, por pequeña que ésta sea. Se trata de un conjunto al que se puede atribuir una dimensión 'fractal'. Los atractores de este tipo implican, por parte del sistema al que caracterizan, un comportamiento de tipo caótico. Atractor y estabilidad dejan de ir juntos a partir de este punto (PRIGOGINE; STENGERS, 1994, p. 14).

Estos «atractores extraños» constituyen una ampliación de la teoría de los sistemas dinámicos. Ahora, los sistemas estables son sólo un caso límite de los sistemas inestables y los atractores estables un caso límite de los «atractores extraños». Que el sistema dinámico se 
encuentre en un "atractor extraño» implica que es estable estructuralmente o globalmente, pero inestable a nivel local. Es decir, los estados posibles del sistema están dentro de una región determinada del espacio de fases, pero dentro de ella, el sistema «salta» impredeciblemente de un punto a otro, siguiendo una «trayectoria» caótica. Ejemplo de esta situación es el tiempo atmosférico. El atractor correspondería a un cierto clima, ya sea tropical, lluvioso, templado, etc. Pero dentro de un determinado clima el tiempo meteorológico diario es impredecible más allá de un cierto «horizonte temporal».

Otro ejemplo usado habitualmente por Prigogine es un modelo abstracto que representa una transformación o aplicación matemática que constituye una suerte de sistema mezclador, es la llamada «transformación del panadero», por la similitud de la transformación con los movimientos de estiramiento y doblamiento de la masa que realiza el panadero (PRIGOGINE; STENGERS, 1994, p. 273). En este modelo de sistema inestable se conjugan orden y caos. La regularidad de la transformación a nivel global produce una distribución caótica a nivel local, que implica una aleatoriedad irreducible. «La descripción de una región, no importa lo pequeña que sea, es básicamente estadística. [...] [Entonces,] sólo podemos hablar de la probabilidad de que un sistema cuya condición inicial corresponde a una región, siga tal o cual tipo de trayectoria» (PRIGOGINE; STENGERS, 1994, p. 274).

Las variables de los sistemas dinámicos tienen frecuencias propias o modos propios de vibración (en el caso de los sistemas cuyo comportamiento está dado por un punto fijo en el espacio de fases, la frecuencia es cero). «Cada uno de los grados de libertad [variables del sistema] de un sistema dinámico se caracteriza por una frecuencia. El valor de las diferentes frecuencias en general depende del punto del espacio de las fases» (PRIGOGINE, 1996, p. 43). Las variables de los sistemas (y por tanto los sistemas) entran en relaciones de acoplamiento (enganches y desenganches, por así decir) dentro de las cuales destaca la resonancia que implica un refuerzo de regularidades. ¿En qué consiste la resonancia? 
La noción de resonancia caracteriza una relación entre frecuencias. Un ejemplo simple de frecuencia es el del oscilador armónico [...] Consideremos ahora el tipo más familiar de oscilador, el resorte que, alejado de su posición de equilibrio vibra con una frecuencia característica. Sometamos dicho resorte a una fuerza externa, también caracterizada por una frecuencia que podamos variar. Observamos entonces un fenómeno de acoplamiento entre dos frecuencias. La resonancia se produce cuando las dos frecuencias - la del resorte y la de la fuerza externa- corresponden a una relación numérica simple (una de las frecuencias es igual a un múltiplo entero de la otra). La amplitud de la vibración del péndulo aumenta entonces considerablemente. En música se produce el mismo fenómeno, cuando tocamos una nota en un instrumento. Oímos las armónicas. La resonancia "acopla" los sonidos (PRIGOGINE, 1996, p. 43).

Las resonancias dependen entonces de la relación numérica entre las frecuencias de las variables del o los sistemas. Si la relación es racional, es decir, expresable como una razón de números enteros n/m, entonces las frecuencias se combinan y se produce un movimiento sincronizado, están en resonancia, lo que da lugar a movimientos regulares. Si la relación numérica es irracional, es decir, si la división entre ellos no corresponde a un número entero, entonces las frecuencias son independientes, los sistemas son asincrónicos, lo que da lugar a movimientos irregulares o caóticos (STEWART, 2001, p. 268).

Veamos a continuación cómo interpretar El año pasado en Marienbad, a partir de los conceptos esbozados en esta sección.

\section{El año pasado en Marienbad como un sistema dinámico de imágenes inestable}

Consideremos El año pasado en Marienbad, como un sistema dinámico de imágenes inestable o caótico, compuesto por subsistemas: el sistema visual y el sistema sonoro (con sus respectivas variables o grados de libertad: plano, cámara, palabras, sonidos, etc.). A su vez, el sistema sonoro puede subdividirse en dos subsistemas (no los únicos): el sistema parlante y el sistema musical. Los sistemas visual y sonoro 
(parlante y musical) entrarán en relaciones sincrónicas o asincrónicas. Así, en algunos momentos parecerá que sus respectivas trayectorias convergen y se anudan en un movimiento regular, compartiendo un mismo tiempo, mientras que en otros momentos sus trayectorias serán divergentes, independientes entre ellas, llevando a un movimiento caótico al sistema Marienbad. Respecto a los sistemas visual y parlante Deleuze nos dice:

En El año pasado en Marienbad y en toda su obra, Robbe-Grillet hacía jugar una nueva asincronía, donde lo parlante y lo visual ya no pegaban, ya no se correspondían, sino que se desmentían y se contradecían, sin que podamos dar 'razón ' a uno más que al otro, algo indecidible entre los dos (como observa Gardies, lo visual no tiene ningún privilegio de autenticidad y no supone menos inverosimilitudes que la palabra). Y las contradicciones ya no nos dejan simplemente confrontar lo oído y lo visto vez por vez, o uno por uno, pedagógicamente: su función es inducir un sistema de desenganches y de entrelazamientos que determinan a su turno los diferentes presentes por anticipación o retrogradación, en una imagen-tiempo directa, o bien organizan una serie de potencias, retrogradable o progresiva, bajo el signo de lo falso. Lo visual y lo parlante pueden encargarse en cada caso de la distinción de lo real y de lo imaginario, tan pronto uno, tan pronto otro, como de la alternativa de lo verdadero y lo falso; pero una sucesión de imágenes audiovisuales necesariamente vuelve indiscernible lo distinto, e indecidible la alternativa (2004, p. 330).

De acuerdo a lo anterior, podemos hablar también de sincronías como entrelazamientos y de asincronías como desenganches.

Desde un punto de vista meramente dinámico diremos que el sistema Marienbad corresponde a un «atractor extraño», pues su comportamiento no es completamente caótico ni completamente ordenado, sino que comparte algo de ambos, se encuentra en un «punto medio», en un «entre» el caos absoluto y el orden absoluto, pues como veíamos un «atractor extraño» permite semejante flexibilidad. También el sistema visual y el sistema sonoro están representados por «atractores extraños». 
Ahora veamos con más detalle los sistemas parlante y musical, que forman parte del sistema sonoro. La estabilidad global del sistema parlante está dada por la repetición constante de palabras, frases, oraciones, etc., por el ritmo pausado, monótono, poético. Por ejemplo: «X: salones vacíos, corredores, salones, puertas, puertas, salones, sillas vacías, profundos armarios, escaleras, escalones, escalones, uno tras otro...». $\mathrm{Su}$ aspecto aleatorio lo representan bien los cambios de tiempos verbales, las ambigüedades en algunos diálogos («A:Yo nunca he estado en Frederiksbad, X: Entonces quizás fuera en algún otro lugar: Karlstadt, Marienbad, o Baden-Salsa o puede que fuera aquí, en este salón»), los diversos sentidos de las frases, etc. En el caso del sistema musical, la estabilidad global está dada principalmente por el «color» del sonido del órgano que corresponde a casi el único instrumento presente en todo el film, sólo en un par de ocasiones suenan algunos violines. A nivel local la música es disonante, serial, como si consistiera de bloques de música que se siguen de manera aleatoria. Así, la música va cambiando su intensidad, su volumen, su ritmo, a través de toda la película.

Veamos algunos ejemplos de interacción entre los sistemas. El comienzo de la película a nuestro juicio representa una situación sincrónica, resonante, que genera una atmósfera hipnótica, expectante. Vemos la cámara fluir por los techos y decorados del palacio, con movimientos muy suaves como en casi todo el film. Las palabras, cadenciosamente, van y vienen, repitiéndose algunas, en especial «couloir», como en una especie de mantra. La música de órgano contribuye a esta atmósfera con acordes disonantes. Minuto 22 de la película encontramos una asincronía visual-parlante. $X$ está jugando con $\mathrm{M}$ y se comienza a escuchar su voz en off, describiendo el hotel: «Una vez más yo avancé solo, a lo largo de estos mismos corredores, a través de las mismas habitaciones desiertas, pasando los mismos portales, las mismas galerías sin cristal, cruzando los mismos umbrales, tomando este camino del laberinto como si por casualidad». Mientras X habla, lo único que vemos es a dos hombres jugando. No hay música mientras habla. Luego que el hombre $X$ ha perdido en el juego, comienza la música del órgano, $\mathrm{X}$ mira a $\mathrm{M}$ y se produce el cambio de escena. Alrededor del minuto 30, se presenta una nueva asincronía entre imagen-visual 
e imagen-parlante. Como pasa bastante seguido en el film, lo parlante anticipa la escena siguiente o continúa después de concluida ésta, otorgando una continuidad entre escena y escena. $X$ dice: «¿Dónde? Eso no importa. Tú estabas con un grupo de amigos. Gente a la que yo apenas conocía; y probablemente tú tampoco. Discutían de algo de lo que yo no sabía nada. Tú sabías algo más del tema, probablemente. Yo te observaba. Tu animada conversación me pareció artificial y falsa...». Mientras X dice esto, vemos a A caminando sola por el jardín como asustada, buscando a alguien, con un zapato en la mano. Lo que vemos y oímos no coinciden para nada, no resuenan en absoluto. En el minuto 42 del film encontramos una asincronía entre sistema visual y sistema musical. El sistema parlante está prácticamente ausente. Vemos a X y A sentados en un salón asistiendo a un concierto de un dúo de violines, pero oímos un órgano interpretando enérgicamente. Estos son sólo unos pocos ejemplos que hemos considerado pertinentes para aclarar las ideas.

Detengámonos en el sistema visual. Las imágenes realizan saltos irracionales, saltos al afuera.

Lo que cuenta no es la asociación de las imágenes, la forma en que se asocian, sino el intersticio entre dos imágenes; [...] el corte en una secuencia de imágenes no es un corte racional que señala el fin de una $o$ el comienzo de otra, sino un corte llamado irracional que no pertenece a ninguna de las dos, y que comienza a valer por sí mismo (DELEUZE, 2004, p. 265).

El intersticio abre un antes y un después no presentes directamente en las imágenes, un mundo propio, mundos posibles en un mismo mundo, al igual que los «presentes simultáneos».

Estos puntos irracionales se corresponden con los puntos de bifurcación, de los sistemas de no equilibrio. «En estos puntos el comportamiento del sistema se hace inestable y puede evolucionar hacia varios regímenes de funcionamiento estables. En tales puntos, un 'mejor conocimiento' no nos permitirá deducir lo que sucederá ni sustituir las probabilidades por certezas» (PRIGOGINE; STENGERS, 1990, p. 69). En el punto de bifurcación, el sistema tiene la posibilidad de «elegir» 
entre dos o más estados igualmente posibles. En general, existen influencias externas, como puede ser el campo gravitatorio, que rompen la simetría y cargan la balanza hacia un determinado estado estable. Sin embargo, estas alteraciones externas que condicionan la «elección» sólo podemos constatarlas, mas no predecirlas.

El valor que adquiere el intersticio entre las imágenes en el cine de la imagen-tiempo, en especial en Godard (DELEUZE, 2004, p. 251), y la importancia de la teoría de las bifurcaciones en la ciencia son muestra de ciertas resonancias en estos campos, o maneras similares de abrir nuevos horizontes de comprensión (DELEUZE, 2004, p. 162). En el caso de la ciencia:

Sabemos hoy que un mismo sistema puede, a medida que se hace crecer su distancia al equilibrio, atravesar múltiples zonas de inestabilidad en las que su comportamiento se transformará de manera cualitativa. Podrá, en particular, alcanzar un régimen caótico en el que su actividad puede definirse como lo contrario del desorden indiferente que reina en el equilibrio: ninguna estabilidad asegura ya la pertinencia de una descripción macroscópica, todos los posibles se actualizan, coexisten e interfieren, el sistema es 'al mismo tiempo' todo lo que puede ser (PRIGOGINE; STENGERS, 1990, p. 69) ${ }^{3}$.

El texto destacado resuena con las nociones de pasados coexistentes, presentes simultáneos e intersticios entre imágenes. «La línea recta como fuerza del tiempo, como laberinto del tiempo, es también la línea que se bifurca y no cesa de bifurcarse, pasando por 'presentes incomposibles', volviendo sobre 'pasados no necesariamente verdaderos'» (DELEUZE, 2004, p. 177).

Una de las variables destacables del sistema visual de Marienbad, es el plano. Todo el film parecería estar constituido por un único plano secuencia, otorgando así una estabilidad global, que es sin embargo engañosa. En realidad lo que hay es un plano secuencia por montaje. Plano secuencia y montaje se entremezclan de manera que es difícil distinguir lo continuo y lo discontinuo. Un ejemplo de esto

3 El subrayado es nuestro.

Rev. Filos., Aurora, Curitiba, v. 29, n. 46, p. 51-72, jan./abr. 2017 
es una toma donde $\mathrm{M}$ está de pie y la cámara realiza un travelling hacia la derecha, por donde va apareciendo una segunda habitación donde está sentado X. La imagen de $\mathrm{M}$ va desapareciendo por la izquierda y aparece en la otra habitación. A todas luces parece ser un plano continuo de izquierda a derecha, pero hay un detalle en la imagen que deja en evidencia el montaje. Poco antes de desaparecer la imagen del hombre $\mathrm{M}$ por la izquierda de la pantalla, se ve parte de su brazo, que de pronto desaparece, evidenciando el corte. Con esto queremos mostrar cómo a través del montaje Resnais produce un plano continuo.

Otra variable a destacar es la cámara. El movimiento de la cámara es un constante travelling, un fluir, que tiene una personalidad propia, otorgando nuevamente una suerte de estabilidad global, que sin embargo implica a la vez inestabilidad o irregularidad a nivel local. La cámara es un personaje más, que «voluntariamente» avanza siguiendo un personaje $u$ otro, examinando un lugar $u$ otro, etc. El uso que hace Resnais del travelling constituye una imagen-tiempo directa, y es uno de los sellos inconfundibles de su estilo de filmación. Recordemos el uso que hizo del travelling en Nuit et Brouillard recorriendo los campos de concentración abandonados, en Hiroshima mon amour, recorriendo las calles de la nueva Hiroshima y de Hiroshima-Nevers, etc. «Los travellings de Resnais [...] operan una temporalización de la imagen o forman una imagen-tiempo directa, que satisface el principio: la imagen cinematográfica no está en presente más que en los malos films» (DELEUZE, 2004, p. 61).

También los falsos-raccord (papel importante juega el vestuario) contribuyen a esta sensación de continuidad-discontinuidad en el film. Un ejemplo extraordinario de esto es cuando la mujer A va caminando con $X$ por un pasillo del hotel en el cual hay otras parejas conversando y los observan. De pronto están en otro pasillo vacío. El punto de continuidad lo da el movimiento de la pierna de A que «entra» en el plano siguiente.

Veamos con más detalle lo que se refiere al sistema parlante. 
La narración consistirá en distribuir los diferentes presentes por los diversos personajes, de suerte que cada uno de ellos forme una combinación plausible, posible en sí misma, pero que todas juntas sean 'imcomposibles' [imcompossibles], y que así lo inexplicable sea mantenido, suscitado. En El año pasado en Marienbad, es X el que conoció a A (y por tanto A no se acuerda o miente), y es A la que no conoce a $\mathrm{X}$ (y por tanto $\mathrm{X}$ se equivoca o miente). Finalmente los tres personajes $[\mathrm{A}, \mathrm{X}, \mathrm{M}]$ corresponden a los tres presentes diferentes, pero de tal manera que 'complican' lo inexplicable en lugar de aclararlo, de tal manera que lo hacen existir en vez de suprimirlo: lo que $X$ vive en un presente de pasado, A lo vive en un presente de futuro, a tal extremo que la diferencia segrega o supone un presente de presente (el tercero, el marido), todos implicados unos en otros (DELEUZE, 2004, p. 139).

Así, tenemos «bloques de presente» que representan el pasado, presente y futuro del acontecimiento. Podemos imaginarnos estos bloques en un espacio ergódico como el que produce la «transformación del panadero», todos igualmente probables.

Otro aspecto importante en la «narración» de Robbe-Grillet son las descripciones, que crean su propio objeto, lo falsifican y no siempre se ven confirmadas por lo que la imagen-visual muestra (DELEUZE, 2004, p. 141). El hombre X, que es el que «narra» y describe en el film, puede ser considerado como un falsario, en tanto intenta convencer a A de algo que quizás no sucedió (su encuentro el año pasado), y las descripciones de los momentos que supuestamente compartieron juntos quedan, en general, en entredicho. Veamos algunos ejemplos. «Era como si no hubiera nadie más en el jardín, sólo tú y yo. Charlábamos despreocupados: de los nombres de las estatuas, de las formas de los arbustos, de los estanques ornamentales. O puede que no habláramos». En otra ocasión $X$ dice: «Estabas sentada en la cama, con una toga o bata blanca. Estabas vestida de blanco, con zapatillas blancas también, llevabas este anillo. - Estoy segura de que lo inventas todo. Nunca he tenido una bata blanca. Estás pensando en otra persona. - Si tú lo dices».

Acerca de la figura del falsario, Deleuze nos dice: 
El falsario podía existir antes bajo una forma determinada que podía ser la del mentiroso o el traidor, pero ahora adquiere una figura ilimitada que impregna a todo el film. A la vez es el hombre de las descripciones puras y fabrica la imagen-cristal, la indiscernibilidad de lo real y lo imaginario; pasa al cristal y hace ver la imagen-tiempo directa; suscita las alternativas indecidibles, las diferencias inexplicables entre lo verdadero y lo falso, y con ello mismo impone una potencia de lo falso como adecuada al tiempo, por oposición a cualquier forma de lo verdadero que disciplinaría al tiempo (2004, p. 179).

Quizá Robbe-Grillet esté en lo cierto al decir que todo pasa en la cabeza del protagonista, de este falsario que es el hombre X. Pero al mismo tiempo, no es sólo una mentira abstracta que cae por su propio peso, como en el caso del mentiroso. Al contrario, es concreta, real y nos atrapa, dejándonos al mismo tiempo en la duda acerca de qué es real y qué imaginario.

\section{Acerca del espacio y los cuerpos en El año pasado en Marienbad}

En El año pasado en Marienbad es llamativo el contraste que se produce entre las líneas rectas del jardín y las líneas sinuosas del interior del hotel. El diseño del jardín es en general regular, simétrico, equilibrado, mientras que el hotel es irregular, asimétrico, recargado. Si el jardín es un buen ejemplo de la claridad en las estructuras, el interior del hotel es confusión de figuras, ornamentos, etc., combinada en un constante juego de espejos. El espacio configurado por el jardín es un espacio euclidiano, mientras que el espacio interior del hotel es un espacio no euclidiano, temporalizado, heterogéneo, probabilístico. Nuevamente encontramos aquí un sutil juego de orden y caos, de homogeneidad y heterogeneidad que es propio de sistemas inestables. Tal como afirma Prigogine en relación a la inestabilidad de Bénard (DURÁN, 2013, p. 142):

En la inestabilidad de Bénard podemos observar por ejemplo un estrato caliente superpuesto a un estrato frío. O bien corrientes de convección dotadas de estructuras coherentes que van por ejemplo de derecha a 
izquierda, o viceversa. Estas estructuras rompen la simetría euclidiana del espacio. En el equilibrio o cerca del equilibrio, todos los puntos que yacen sobre un mismo plano tienen las mismas propiedades. Lejos del equilibrio aparecen zonas de quiralidad opuesta. Ha habido pues una ruptura de la simetría del espacio del mismo modo que, en los fenómenos temporales, el fenómeno irreversible provoca la ruptura de la simetría del tiempo (1998, p. 85).

Podemos hablar, entonces, de una temporalización del espacio, que rompe con las simetrías. Deleuze lo expresa de la siguiente manera en relación a los espacios configurados por Robbe-Grillet y Resnais:

Al mismo tiempo que el espacio concreto deja de ser hodológico, el espacio abstracto deja de ser euclidiano, perdiendo a su vez las conexiones legales y las leyes de extremo que las regían [...] Podemos hablar de [...] de espacios cuánticos en Robbe-Grillet, de espacios probabilísticos y topológicos en Resnais (2004, p. 175).

Debemos considerar ahora la imagen-tiempo directa que nos ofrecen los cuerpos. En primer lugar los personajes extra. Éstos tienen escasa participación en la trama y lo que los caracteriza principalmente con respecto a su movimiento, es justamente su carencia. Generalmente quietos se activan aleatoriamente o dependiendo del movimiento de los protagonistas. Un ejemplo claro se da al comienzo, después de finalizada la obra de teatro, cuando se muestra a la gente conversando, la cámara se pasea por los salones y de un momento a otro se quedan quietos y luego se activan. Se activan y desactivan aleatoriamente. También se ha visto en los movimientos realizados por los personajes extra una especie de gran ritual o ceremonial. «La música de órgano y la gravedad como de iglesia o funeral; la repetición de fórmulas, movimientos rituales y la uniformidad del vestir; y el despliegue ocasional de imaginería cruciforme sugieren una dimensión religiosa» (O’DONOGHUE, 2004). El carácter casi estático de los movimientos de los personajes extra, resuena con la música repetitiva del órgano, otorgando una estabilidad casi ceremonial a la película en su conjunto, mientras que considerados en sí mismos, sus movimientos resultan aleatorios, irregulares. 
En segundo lugar, la mujer A, cuyas actitudes, gestos y movimientos constituyen con toda propiedad una imagen-tiempo hecha cuerpo. Resnais se ocupó con mucho cuidado del personaje de A. Robbe-Grillet dice: «Resnais se interesó por su personaje y en realidad fue en gran parte creado por él. En mi versión la mujer era una especie de estatua más carnal y más opaca» (PEÑA, s.f.). Los movimientos y gestos de A, siempre plásticos, fluidos, suaves, sutiles, cadenciosos, contrastan con la carencia de movimiento de los personajes extra, con los también escasos movimientos de $\mathrm{M}$, siempre muy mecánicos, casi robóticos y con la actitud parca y severa, como ido, de X. En el guión son frecuentes las descripciones que dan cuenta de las actitudes, gestos y características físicas de A. Por ejemplo: «Conservas la misma mirada soñadora en tus ojos, la misma sonrisa, la misma risa repentina, el mismo brusco movimiento de tu brazo, el mismo modo de descansar la mano en tu hombro y todavía usas el mismo perfume». «Estabas sola, apartada, inclinada sobre la balaustrada de piedra, sobre la que posabas tus manos, con los brazos un poco extendidos». Quizá cada gesto y actitud de A constituya un corte irracional, un salto al afuera que lleva a $\mathrm{X}$ a vagar por los fragmentos de su memoria. Recordemos la escena en que $\mathrm{X}$ y A están en el concierto del dúo de violines. A posa su mano sobre su hombro, $\mathrm{X}$ la mira atentamente, saltamos a otra imagen, a otra escena en que A está en la misma posición, sirviendo de continuidad y al mismo tiempo de salto entre una escena y otra. Los movimientos de A, con su fluidez, al igual que los travellings dotan de cierta estabilidad global a la película, al tiempo que a nivel local, sus gestos resultan aleatorios, impredecibles.

Por último, recordemos que esa imagen-tiempo directa de los cuerpos, de los gestos, de las actitudes, de los movimientos o de su carencia, está presente en otros films de Resnais. Por ejemplo, en Hiroshima mon amour, la actriz francesa actualiza una imagen de su pasado al ver el gesto de la mano del japonés dormido. También los cuerpos de las víctimas de los campos de concentración en Nuit et Brouillard. Los cuerpos contorsionados, desgarrados, que vemos a través de la pintura de Piccasso en Guernica. Por último, un ejemplo realmente extraordinario de imagen-tiempo directa hecha cuerpo es la escena inicial de Hiroshima 
mon amour. Esos cuerpos entrelazados, que se metamorfosean, que son ceniza, carne, sudor, todo a la vez. Siempre quedan cortas las palabras, especialmente cuando se trata de describir imágenes de tal potencia, más vale verlas directamente.

\section{Conclusiones}

Hemos visto cómo, los conceptos y nociones ofrecidos por la teoría de sistemas dinámicos inestables, tal como es usada y expuesta por Prigogine, constituyen un rico conjunto interpretativo, que nos ha permitido estudiar El año pasado en Marienbad de Resnais, y sus sutiles juegos de regularidad e irregularidad, sincronía y asincronía, orden y caos. Las ideas de Prigogine nos han permitido analizar la sutil coherencia en tensión de la película de Resnais, que, tal como afirma Deleuze, puede atribuirse en cierta medida a su doble autoría ResnaisRobbe-Grillet. La dinámica de imágenes del que hemos llamado «sistema Marienbad», puede asociarse a una suerte de «atractor extraño», combinando estabilidad e inestabilidad, orden y caos. Esta misma dinámica se da en sus subsistemas, visual y sonoro (parlante y musical), que entran en diversas relaciones de sincronía y asincronía, de regularidad e irregularidad.

Digamos, finalmente, que el objetivo de nuestro artículo, siguiendo lo expresado por Deleuze y Prigogine ${ }^{4}$, no ha sido reducir la película El año pasado en Marienbad a una teoría científica, ni mucho menos, sino poner en resonancia, como una suerte de experimento virtual, ideas, conceptos y modelos pertenecientes a registros distintos, a diferentes áreas del conocimiento y la creatividad humanos, pero que apuntando

4 Deleuze: «Conocemos, es verdad, los peligros de invocar determinaciones científicas fuera de su terreno. Está el peligro de una metáfora arbitraria, o bien de una aplicación trabajosa. Pero estos peligros quizá pueden conjurarse si nos limitamos a extraer de los operadores científicos tal o cual rasgo conceptualizable que remite él mismo a dominios no científicos, y que converge con la ciencia sin caer en la aplicación ni en la metáfora» (Deleuze, 2004, p. 175). Prigogine y Stengers afirman: «Con el mismo título que el arte y la filosofía, la ciencia es ante todo experimentación, creadora de preguntas y significados» (1990, p. 19). 
en direcciones similares se refuerzan de manera recíproca, abriendo nuevas vías de comprensión, nuevos significados, nuevas preguntas.

\section{Referencias}

BERGSON, H. Materia y memoria. Buenos Aires: Cactus, 2006.

DELEUZE, G. La imagen-tiempo: Estudios sobre cine 2. Barcelona: Paidós, 2004.

DELEUZE, G. Kant y el tiempo. Buenos Aires: Cactus, 2008.

DURÁN, R. Autoorganización y estructuras disipativas. La imagen de naturaleza en Ilya Prigogine. Tesis de Doctorado en Filosofía. P. Universidad Católica de Valparaíso, Valparaíso, 2013.

KIRSCH, W. Marienbad Revisited: A Feast for the Senses. Creative Screenwriting, v. 3, n. 1, 1996.

LOSILLA, C. La perversidad del cine moderno o breve guía para pasear por Marienbad. Cameo Media S. L., 2009.

PEÑA, F. M. El año pasado en Marienbad. Entrevista con Alain RobbeGrillet,[en línea]. MALBA Museo de Arte Latinoamericano de Buenos Aires - Cine. Disponible en: <http://intranet.malba.org.ar/web/cine_pelicula. php?id=137>. Accedido el: 11 septiembre 2016.

O'DONOGHUE, D. L'année dernière à Marienbad (Last Year at Marienbad). Senses of cinema, n. 33, oct, 2004. Disponible en: <http://sensesofcinema. com/2004/cteq/last_year_at_marienbad/>. Accedido el: 1 marzo 2016.

PRIGOGINE, I. El fin de las certidumbres. Santiago de Chile: Andrés Bello, 1996.

PRIGOGINE, I. El nacimiento del tiempo. Barcelona: Tusquets, 1998. 
72 ALLIMANT, R. D.

PRIGOGINE, I.; STENGERS, I. Entre el tiempo y la eternidad. Madrid: Alianza, 1990.

PRIGOGINE, I.; STENGERS, I. La nueva alianza. Madrid: Alianza, 1994.

STEWART, I. ¿Juega Dios a los dados? Barcelona: Crítica, 2001.

Recebido: 20/11/2016

Recibido: 11/20/2016

Aprovado: 15/01/2017

Aprobado: 01/15/2017 